\title{
Histopathological changes in the lungs of rats instilled with Korean chrysotile
}

\author{
Jeong Hee Han ${ }^{1}$, (D) Yong Hyun Chung ${ }^{2}$, Cheol Hong Lim ${ }^{1}$ \\ ${ }^{1}$ Chemicals Safety and Health Research Center, Chemical Research Bureau, Occupational Safety and Health Research \\ Institute, Korea Occupational Safety and Health Agency, Daejeon, Republic of Korea \\ ${ }^{2}$ Korean Medicine Preclinical Trial Center, National Institute for Korean Medicine Development, Jangheung, Republic of \\ Korea \\ *Correspondence: hanjh@kosha.or.kr
}

Received: May 12, 2020 Accepted: July 2, 2021

\begin{abstract}
To evaluate the pulmonary toxicity of Korean chrysotile (KC), 1 or $2 \mathrm{mg}$ of $\mathrm{KC}$ (low- and high-concentration groups, respectively) was instilled in the lungs of Sprague-Dawley rats by a single intratracheal instillation. The lungs were examined using a light microscope at several time points ( 5 days, 5 weeks, and 10 weeks). Up to 10 weeks after KC instillation, differences were observed in the pathological reactions and ultimately in lung recovery between the two groups. At 5 days after $\mathrm{KC}$ instillation, lung weight increased and severe bronchiolitis obliterans developed in proportion to the $\mathrm{KC}$ concentration administered. From 5 to 10 weeks after KC administration, the lung weight of the low-concentration group increased and bronchiolitis obliterans worsened. In the high-concentration group, the lung weight and the severity of bronchiolitis obliterans at 10 weeks after administration of KC declined compared to those at 5 weeks. In conclusion, the effects of KC on lung tissue were initially found to be more influenced by the amount of fiber, but over time, the effects were influenced by the residual fibrous material in the lung tissue and its biodurability.
\end{abstract}

Keywords: Korean chrysotile, Intratracheal instillation, Rat

\section{Introduction}

The in vivo response to toxic fibrous mineral materials varies based on the materials' properties, biodurability, fiber size and the amount inhaled. Asbestos minerals can be classified into serpentine and amphibole, according to the physical and chemical properties of fibers. There are chrysotile which is a serpentine mineral and asbestiform of amosite, crocidolite, tremolite, actinolite, anthophyllite which is a amphibole. It is known that an amphibole is a stronger and more durable compared with serpentine [1]. Pulmonary fibrosis and proliferative responses were observed in the bronchiole of mice exposed to crocidolite fibers longer than $20 \mu \mathrm{m}$, but not to those shorter than $1 \mu \mathrm{m}[2,3]$. It is known that exposure of the respiratory system to chrysotile does not result in a histopathological response because of chrysotile's low biodurability. However, amosite remains in the lungs and causes pulmonary fibrosis at 5 days after exposure [4-6]. There was no pathological response in the lungs and pleura of rats exposed to chrysotile levels more than 5,000 times the threshold limit value (TLV) established by the American Conference of Industrial Hygienists. Slight fibrosis was noted in the lungs and pleura exposed to chrysotile levels more than 14,000 times the TLV; however, the chrysotile rapidly cleared from the lungs and there was no pulmonary fibrosis around the pleura [7]. Granuloma and inflammation developed in the lungs of experimental animals exposed to amphibole asbestos types such as tremolite and amosite for 5 days, and interstitial fibrosis was observed at 28 days after cessation of exposure. Lungs exposed to amosite higher than $20 \mu \mathrm{m}$ showed residual asbestos for as long as 1 year after cessation of exposure [4-6]. The purpose of this study was to determine the effect of Korean chrysotile (KC) on lung tissue and examine the changes in lung tissue over time after instillation of KC at both low and high concentrations into the respiratory tract of rats.

\section{Materials and Methods Test material.}

The test material was used chrysotile collected from asbestos deposits in Chungcheongnamdo, which is where most of the asbestos in Korea is produced. The properties of the test material were compared with the International Union against Cancer (UICC) standard chrysotile purchased from General Science Cooperation (Tokyo, Japan) (Figure 1 and Table 1). The number of fibers in the test material (average size, $0.08 \mu \mathrm{m} \times 4.74 \mu \mathrm{m}$ ) was $59,043 \times 10^{6}$ fibers $/ \mathrm{mg}$. The size distribution 
of the fibers of the test material was as follows: $99 \%$ of the fibers had a diameter less than $0.25 \mu \mathrm{m}, 33 \%$ of the fibers had a length greater than $5 \mu \mathrm{m}$, and $67 \%$ of the fibers had a length less than $5 \mu \mathrm{m}$.

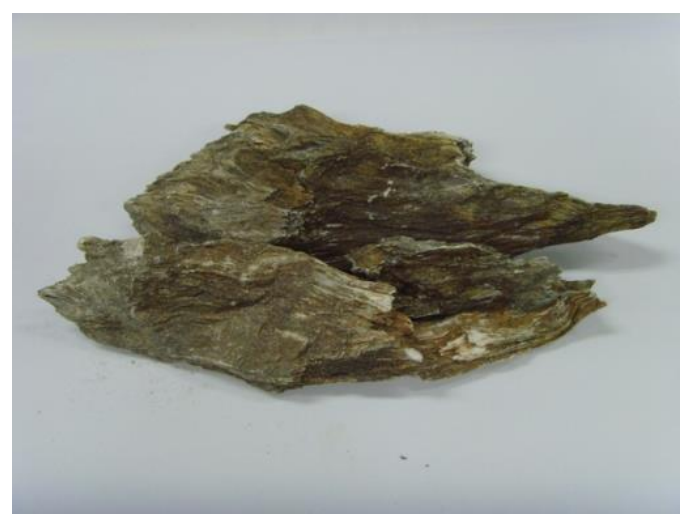

Figure 1. Picture of Korean chrysotile

Table 1. Size and element composition (atomic \%) of chrysotile.

\begin{tabular}{|c|c|c|c|c|c|}
\hline & Diameter & Length & Mg & Si & $\mathrm{Fe}$ \\
\hline Standard chrysotile & $0.03 \pm 0.03$ & $5.50 \pm 5.26$ & $58.07 \pm 0.82$ & $40.50 \pm 0.92$ & $1.43 \pm 0.13$ \\
\hline Korean chrysotile & $0.08 \pm 0.07$ & $4.39 \pm 3.61$ & $57.51 \pm 0.86$ & $41.57 \pm 0.85$ & $0.93 \pm 0.19$ \\
\hline
\end{tabular}

\section{Animal husbandry and maintenance.}

Seven-week-old specific-pathogen-free male Sprague-Dawley (SD) rats were obtained from Central Lab. Animal Inc. in Korea. Healthy animals were chosen and used after acclimation in the clean animal room for a week. The following conditions were maintained in the animal room: temperature, $22 \pm 3{ }^{\circ} \mathrm{C}$; relative humidity, $50 \pm 20 \%$; air change, $13 \sim 18$ times per hour; illumination intensity, 150 300 lux; and artificial lighting, lights on from 08:00 to 20:00 (12 hours). The rats were allowed free access to a commercial rodent diet (Labdiet 5053, PicoLab Rodent Diet, USA) and ultrafiltered, UV-sterilized tap water. The study was approved by the Institutional Animal Care and Use Committee of Inhalation Toxicity Research Center.

\section{Experimental groups.}

The rats were split into three main groups: low-concentration, high-concentration and control. The test material was instilled into the animals and each groups was sub-divided by treatment length -5 days, 5 weeks, or 10 weeks-(5 rats per sub-group) so as to minimize the effects of weight deviations in the groups.

\section{Method for administering the test material.}

Each animal was anesthetized with ketamine (Yuhan Pharm, Korea) and then administered KC by a single intratracheal instillation. The low-concentration group was instilled with $1 \mathrm{mg}$ of $\mathrm{KC}$ diluted with $0.3 \mathrm{ml}$ of saline, and the high-concentration group was instilled with $2 \mathrm{mg}$ of $\mathrm{KC}$ diluted with $0.3 \mathrm{ml}$ of saline [8]. The control group was instilled with only saline.

\section{Body weight and clinical signs.}

Clinical signs were examined once daily after instillation. Body weights were measured at the time of grouping and then weekly.

\section{Lung weight and histopathology.}

The test animals were anesthetized using isoflurane (Ilsung Pharm, Korea), and at the respective times (5 days, 5 weeks, or 10 weeks after $\mathrm{KC}$ instillation), the lungs were removed and weighed. To evaluate the histopathological response, the lung was fixed in $10 \%$ neutral buffered formalin solution. The fixed lung was dehydrated, processed, embedded in paraffin, sectioned with a microtome, and examined under a microscope (AXIOSKOP2 plus, Carl Zeiss, Germany). 


\section{Statistical analysis.}

The results of body and lung weight determinations of the test animals were expressed as average and standard deviation values. Intergroup differences were evaluated using Sigmastat (Systat, San Jose, USA). Groups were compared by one-way analysis of variance (ANOVA) or ANOVA on ranks method. If statistical significance was observed ( $\mathrm{p}<0.05$ ), Dunnett's test was used for multiple comparisons of the control group with each of the experimental groups.

\section{Results}

\section{Changes in body weight.}

Body weight was determined based on the lapse of time after KC instillation. At 5 days after KC instillation, the body weight of the low-concentration group was lower than that of the control group; however, the intergroup difference was not significant. Furthermore, at 5 and 10 weeks after $\mathrm{KC}$ instillation, the body weight of the low-concentration group was significantly lower than that of the control group. On the other hand, at 5 days and 5 weeks after KC instillation, the body weight of the high-concentration group was significantly lower than that of the control group. However, at 10 weeks after $\mathrm{KC}$ instillation, although the body weight of the high-concentration group was lower than that of the control group, the intergroup difference was not significant.

A comparison of the body weight changes at 5 days and 5 weeks after $\mathrm{KC}$ instillation between the low- and highconcentration groups indicated that the body weight of the low-concentration group increased compared to that of the highconcentration group. However, at 10 weeks after $\mathrm{KC}$ instillation, the body weight of the high-concentration group increased compared to that after the low-concentration group.

\section{Changes in lung weight.}

Evaluation of the lung weights of the low- and high-concentration groups over time after instillation of $\mathrm{KC}$ showed significantly increased lung weights at 5 days, 5 weeks, and 10 weeks after KC instillation in both groups (Table 2). However, there was a difference in lung weight change with respect to time between the two groups. The lung weight in the low-concentration group increased at 5 days, 5 weeks, and 10 weeks after KC instillation. On the other hand, the lung weight in the high-concentration group increased at 5 weeks compared to that at 5 days but decreased at 10 weeks compared to the weight at 5 weeks. (Table 3) show the results of the comparison of lung weight with the body weight (\%) of the lungs over time after $\mathrm{KC}$ instillation. The lung weight in the high-concentration group was significantly higher than that in the control group. However, changes in lung weight in the low- and high-concentration groups decreased over time.

Table 2. Absolute lung weight of rats instilled with Korean chrysotile.

\begin{tabular}{|c|c|c|c|c|c|c|c|}
\hline \multirow[t]{2}{*}{ Group } & \multirow{2}{*}{$\begin{array}{c}\text { Time point } \\
5 \text { Days }\end{array}$} & \multicolumn{3}{|c|}{ Right lung (unit: mg) } & \multicolumn{3}{|c|}{ Left lung (unit: mg) } \\
\hline & & 772.20 & \pm & 36.04 & 416.80 & \pm & 36.63 \\
\hline \multirow[t]{3}{*}{ Control } & 5 Weeks & 986.20 & \pm & 56.51 & 525.60 & \pm & 44.89 \\
\hline & 10 Weeks & 988.20 & \pm & 40.31 & 528.20 & \pm & 24.57 \\
\hline & 5 Days & 995.80 & \pm & $115.97^{* *}$ & 511.00 & \pm & $51.62^{*}$ \\
\hline \multirow{3}{*}{$\begin{array}{c}\text { Chrysotile } \\
1 \mathrm{mg}\end{array}$} & 5 Weeks & 1117.40 & \pm & $76.59^{*}$ & 582.40 & \pm & $42.96^{*}$ \\
\hline & 10 Weeks & 1157.80 & \pm & $52.03^{* *}$ & 607.60 & \pm & $52.13^{*}$ \\
\hline & 5 Days & 1242.60 & \pm & $71.41^{* *}$ & 629.40 & \pm & $28.32^{* *}$ \\
\hline \multirow[t]{2}{*}{$\begin{array}{c}\text { Chrysotile } \\
2 \mathrm{mg}\end{array}$} & 5 Weeks & 1344.80 & \pm & $99.88^{* *}$ & 707.80 & \pm & $60.25^{* *}$ \\
\hline & 10 Weeks & 1290.20 & \pm & $146.72^{* *}$ & 669.20 & \pm & $99.06^{*}$ \\
\hline
\end{tabular}

${ }^{1}$ All values are expressed as mean \pm SD.

${ }^{2}$ Significant differences as compared with control: ${ }^{* *} \mathrm{p}<0.01,{ }^{*} \mathrm{p}<0.05$ 
Table 3. Relative lung weight and body weight of rats instilled with Korean chrysotile.

\begin{tabular}{|c|c|c|c|c|c|c|c|c|c|c|}
\hline \multirow[t]{2}{*}{ Group } & \multirow{2}{*}{$\begin{array}{l}\text { Time } \\
\text { point }\end{array}$} & \multicolumn{3}{|c|}{$\begin{array}{l}\text { Right lung } \\
\text { (unit:\%) }\end{array}$} & \multicolumn{3}{|c|}{$\begin{array}{l}\text { Left lung } \\
\text { (unit:\%) }\end{array}$} & \multicolumn{3}{|c|}{$\begin{array}{l}\text { Body weight } \\
\text { (unit:g) }\end{array}$} \\
\hline & & 0.268 & \pm & 0.013 & 0.145 & \pm & 0.014 & 288.50 & \pm & 6.56 \\
\hline \multirow[t]{3}{*}{ Control } & 5 Weeks & 0.208 & \pm & 0.011 & 0.111 & \pm & 0.005 & 475.30 & \pm & 34.07 \\
\hline & 10 Weeks & 0.170 & \pm & 0.012 & 0.091 & \pm & 0.003 & 582.50 & \pm & 30.10 \\
\hline & 5 Days & 0.355 & \pm & $0.042^{* *}$ & 0.182 & \pm & $0.018^{* *}$ & 281.00 & \pm & 7.71 \\
\hline \multirow[t]{3}{*}{$\begin{array}{l}\text { Chrysotile } \\
1 \mathrm{mg}\end{array}$} & 5 Weeks & 0.255 & \pm & $0.014^{* *}$ & 0.133 & \pm & $0.009^{* *}$ & 438.10 & \pm & $9.03^{*}$ \\
\hline & 10 Weeks & 0.222 & \pm & $0.019^{* *}$ & 0.116 & \pm & $0.011^{* *}$ & 524.50 & \pm & $41.79^{*}$ \\
\hline & 5 Days & 0.486 & \pm & $0.041^{* *}$ & 0.246 & \pm & $0.010^{* *}$ & 256.30 & \pm & $9.67^{* *}$ \\
\hline \multirow[t]{2}{*}{$\begin{array}{l}\text { Chrysotile } \\
2 \mathrm{mg}\end{array}$} & 5 Weeks & 0.313 & \pm & $0.024^{* *}$ & 0.165 & \pm & $0.015^{* *}$ & 430.10 & \pm & $8.45^{*}$ \\
\hline & 10 Weeks & 0.233 & \pm & $0.024^{* *}$ & 0.120 & \pm & $0.015^{* *}$ & 555.40 & \pm & 43.08 \\
\hline
\end{tabular}

${ }^{1}$ All values are expressed as mean \pm SD

${ }^{2}$ Significant differences as compared with control: ${ }^{* *} p<0.01,{ }^{*} p<0.05$

${ }^{3}$ Relative lung weight: body weight $\%$

\section{Histopathological examination of the lung.}

A histopathological examination of the lung showed slight $(+)$ and moderate (+++) bronchiolitis obliterans in the low- and high-concentration groups, respectively, in proportion to the concentration at 5 days after KC instillation (Table 4). There was minimal (++) and slight (+) bronchiolitis obliterans after KC instillation in one and four rats, respectively, in the low-concentration group; at 10 weeks, all rats showed minimal (++) bronchiolitis obliterans. Thus, bronchiolitis obliterans in the low-concentration group worsened over time.

Moderate (+++) and minimal (+) bronchiolitis obliterans was noted in three and two rats, respectively, in the highconcentration group at 5 weeks after instillation of the KC; however, at 10 weeks after KC instillation, slight (++) and minimal $(+)$ bronchiolitis obliterans was noted in two and three rats, respectively. Thus, in this group, bronchiolitis obliterans alleviated over time.

Table 4. Bronchiolitis obliterans in the lungs of rats instilled with Korean chrysotile.

\begin{tabular}{|c|c|c|c|c|}
\hline Time point & Grade & $\begin{array}{l}\text { Control } \\
(\mathrm{N}=15)\end{array}$ & $\begin{array}{l}\text { Chrysotile } 1 \mathrm{mg} \\
\qquad(\mathrm{N}=15)\end{array}$ & $\begin{array}{c}\text { Chrysotile } 2 \mathrm{mg} \\
(\mathrm{N}=15)\end{array}$ \\
\hline \multirow{3}{*}{$\begin{array}{c}5 \\
\text { days }\end{array}$} & +++ & $0 / 5$ & $0 / 5$ & $5 / 5$ \\
\hline & ++ & $0 / 5$ & $0 / 5$ & $0 / 5$ \\
\hline & + & $0 / 5$ & $5 / 5$ & $0 / 5$ \\
\hline \multirow{3}{*}{$\begin{array}{c}5 \\
\text { weeks }\end{array}$} & +++ & $0 / 5$ & $0 / 5$ & $3 / 5$ \\
\hline & ++ & $0 / 5$ & $1 / 5$ & $0 / 5$ \\
\hline & + & $0 / 5$ & $4 / 5$ & $2 / 5$ \\
\hline \multirow{3}{*}{$\begin{array}{c}10 \\
\text { weeks }\end{array}$} & +++ & $0 / 5$ & $0 / 5$ & $2 / 5$ \\
\hline & ++ & $0 / 5$ & $5 / 5$ & $0 / 5$ \\
\hline & + & $0 / 5$ & $0 / 5$ & $3 / 5$ \\
\hline
\end{tabular}

${ }^{1}+$ : slight, ++: minimal, +++: moderate 


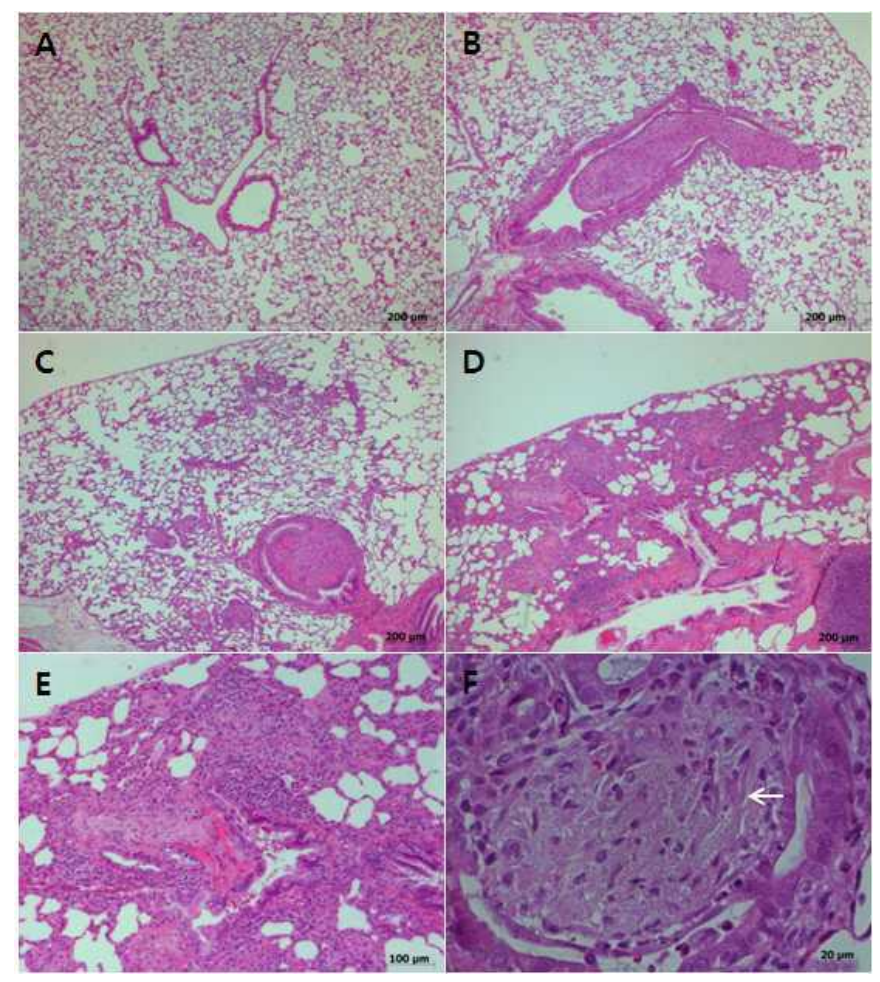

Figure 2. Histopathological findings of the lungs of rats instilled with Korean chrysotile. It was observed hyperplasia of the bronchial epithelial cells, inflammation and fibrosis around bronchioles and blood vessels in bronchiolitis obliterans: (A) Normal lung of the control group at day 5, HE stain, $\times 40$; (B) Bronchiolitis obliterans at day 5 in the high-concentration group, HE stain, $\times 40$; (C)Bronchiolitis obliterans at 5 weeks in the high-concentration group, HE stain, $\times 40$; (D) Bronchiolitis obliterans at 10 weeks in the high-concentration group, HE stain, $\times 40$; (E) Higher magnification of (D), HE stain, $\times 100$; (F) Bronchiolar granuloma (arrow) at day 5 in the high-concentration group, HE stain, $\times 400$.

\section{Discussion}

Fibrous material inhaled into the respiratory system remains in the lung tissue and causes an inflammatory response persistently until it has been completely phagocytosed and removed from the lung by alveolar macrophages [9]. In this study, KC instilled into the trachea of SD rats caused bronchiolar epithelial hyperplasia, bronchiolar and perivascular inflammation, and fibrosis around the bronchioles at the trachea. Bronchiolitis obliterans in the lung tissue after $\mathrm{KC}$ instillation was significantly severe in the high-concentration group compared to that in the low-concentration group during the whole test period ( 5 days, 5 weeks, and 10 weeks). However, the recovery of bronchiolitis obliterans over time was different between the two groups. The low-concentration group showed slight (+) bronchiolitis obliterans at the early stage (day 5); however, the condition worsened with time, at 5 and 10 weeks after KC instillation. In the high-concentration group, all animals showed moderate (+++) bronchiolitis obliterans at the early stage (day 5), but the condition alleviated as time passed, after 5 weeks and 10 weeks. The symptoms of bronchiolitis obliterans progression with regard to the time course differed depending on the concentration of the fibrous material. This suggests that dose of the fibrous material is initially a crucial factor, but the size and biodurability of the fibrous material remaining in the lung tissue over time are important determinants of the toxicity of the fibrous material. In 2015, Chung et al. analyzed fibrous material after intratracheal instillation of $1 \mathrm{mg}$ (low-concentration group) and $2 \mathrm{mg}$ (high-concentration group) of chrysotile in rats under the same test conditions [10]. The analysis of the fibrous material $(\geq 5 \mu \mathrm{m})$ showed that the proportion of the remaining fibers in the lung tissue of the low-concentration group increased over time by $6 \%$ at 5 days, $12 \%$ at 5 weeks, and $17 \%$ at 10 weeks. On the other hand, in the high-concentration group, the proportion decreased by $13 \%$ at 5 days, $11 \%$ at 5 weeks, and $10 \%$ at 10 weeks. In the present study, it was judged that bronchiolitis obliterans in the low-concentration group tended to increase over time after instillation of KC, because the retention rate of the fibrous material with a length of $5 \mu \mathrm{m}$ or more and high biodurability increased, while bronchiolitis obliterans in the high-concentration group tended to decrease as the retention rate of the fibrous material with a length of $5 \mu \mathrm{m}$ or more decreased.

When bronchiolitis obliterans develops, the lung weight changes with the degree of the inflammatory response. In this study, the lung weights of the low- and high-concentration groups significantly increased as time passed after the instillation of the $\mathrm{KC}$, but the changes in lung weight were different between the two groups. The lung weight of the low- 
concentration group increased with time after the instillation, while the lung weight of the high-concentration group increased at 5 weeks compared to that at 5 days but then decreased at 10 weeks. Therefore, it was deduced that the lung recovery reaction, reflected in the changes in lung weights of the low- and high-concentration groups, was consistent with the changes in bronchiolitis obliterans in the lung tissues over time after instillation of $\mathrm{KC}$.

\section{Conclusions}

The lung tissues of the test animals were observed at 5 days, 5 weeks, and 10 weeks after the instillation of a single dose of KC into the trachea of SD rats. Lung tissue recovery did not occur until 10 weeks after the instillation, and the pathological response of the lung tissue was different over time. At 5 days after KC instillation, lung weight increased in proportion to the concentration of KC administered and severe bronchiolitis obliterans developed. At 5 and 10 weeks after KC instillation, lung weight and bronchiolitis obliterans severity increased in the low-concentration group. However, lung weight and bronchiolar obliterans severity in the high-concentration group decreased at 10 weeks compared to those at 5 weeks. Thus, it was concluded that the effect of chrysotile on lung tissue was initially influenced by the fiber content, but over time, it was influenced by the fibrous material remaining in the lung tissue and its biodurability.

\section{Abbreviations}

Korean chrysotile, KC; Sprague-Dawley, SD; threshold limit value, TLV

\section{Acknowledgement}

This article is based on research supported by Korea Occupational Safety and Health Agency, Ministry of Labor, Republic of Korea.

\section{CRediT author statement}

JHH: Review of articles, Conceptualization, Methodology, Formal analysis, Data curation, Writing-Original draft Preparation, Writing-Review and Editing, Visualization; YHC: Conceptualization, Methodology, Validation, Investigation, Data curation, Writing-Original draft Preparation; CHL: Review of articles, Resources, Supervision, Writing-Review and Editing, Project administration.

\section{ORCID}

Jeong Hee Han: 0000-0002-2105-4994

\section{References}

[1] Bernstein D, Dunnigan J, Hesterberg T, Brown R, Velasco JA, Barrera R, et al. Health risk of chrysotile revisited. Crit. Rev Toxicol 2013;43(2):154-183. https://doi.org/10.3109/10408444.2012.756454

[2] Adamson IY, Bakowska J, Bowden DH. Mesothelial cell proliferation after instillation of long or short asbestos fibers into mouse lung. Am J Pathol 1993;142(4):1209-1216.

[3] Adamson IY, Bakowska J, Bowden DH. Mesothelial cell proliferation: a nonspecific response to lung injury associated with fibrosis. Am J Respir Cell Mol Biol 1994;10(3):253-258. https://doi.org/10.1165/ajrcmb.10.3.7509611

[4] Bernstein DM, Chevalier J, Smith P. Comparison of Calidria chrysotile asbestos to pure tremolite: final results of the inhalation biopersistence and histopathology following short-term exposure. Inhal Toxicol 2005;17(9):427-449. https://doi.org/10.1080/08958370591002012

[5] Bernstein DM, Rogers RA, Sepulveda R, Donaldson K, Schule D, Gaering S, et al. The pathological response and fate in the lung and pleura of chrysotile in combination with fine particles compared to amosite asbestos following short-term inhalation exposure: interim results. Inhal Toxicol 2010;22(11):937-962. https://doi.org/10.3109/08958378.2010.497818

[6] Bernstein DM, Rogers RA, Sepulveda R, Donaldson K, Schuler D, Gaering S, et al. Quantification of the pathological response and fate in the lung and pleura of chrysotile in combination with fine particles compared to amosite-asbestos following short-term inhalation exposure. Inhal Toxicol 2011;23(7):372-391 https://doi.org/10.3109/08958378.2011.575413

[7] Bernstein DM, Rogers R, Smith P, Chevalier J. The toxicological response of Brazilian chrysotile asbestos: a multidose subchronic 90-day inhalation toxicology study with 92-day recovery to assess cellular and pathological response. Inhal Toxicol 2006;18(5):313-332. https://doi.org/10.1080/08958370500515871 
Han et al. I Histopathology of Korean chrysotile-instilled rat lungs

[8] Kevin ED, Daniel LC, Gary H, Rogene H, Gunter O, Harry S, et al. Intratracheal instillation as an exposure technique for the evaluation of respiratory tract toxicity : uses and limitations. Toxicol Sci 2000;55(1):24-35. https://doi.org/10.1093/toxsci/55.1.24

[9] Donaldson K, Murphy FA, Duffin R, Poland CA. Asbestos, carbon nanotubes and the pleural mesothelium: a review of the hypothesis regarding the role of long fibre retention in the parietal pleura, inflammation and mesothelioma. Part Fibre Toxicol 2010;7(1):1-17. https://doi.org/10.1186/1743-8977-7-5

[10] Chung YH, Han JH. Evaluation of biodurability of Korean chrysotile within the lung of rats. J. Korean Soc Occup Environ Hyg 2015; 25(1):20-26. https://doi.org/10.15269/JKSOEH.2015.25.1.20 